\title{
Method of Calculating Life-Cycle Fatigue Damage of Orthotropic Steel Bridge Decks under the Combined Actions of Vehicle Loads and Pavement Temperature
}

\author{
Gaoxin Wang $\mathbb{D},{ }^{1}$ Youliang Ding $\mathbb{D}^{2},{ }^{2}$ Zhijun Liu $\mathbb{D}^{1},{ }^{1}$ and Jingshu Shao $\mathbb{D}^{1}$ \\ ${ }^{1}$ State Key Laboratory for Geomechanics and Deep Underground Engineering, China University of Mining and Technology, \\ Xuzhou, China \\ ${ }^{2}$ The Key Laboratory of Concrete and Prestressed Concrete Structures of Ministry of Education, Southeast University, \\ Nanjing 210096, China \\ Correspondence should be addressed to Youliang Ding; civilding@seu.edu.cn
}

Received 20 October 2019; Revised 17 October 2020; Accepted 25 October 2020; Published 4 November 2020

Academic Editor: Baoping Cai

Copyright ( 2020 Gaoxin Wang et al. This is an open access article distributed under the Creative Commons Attribution License, which permits unrestricted use, distribution, and reproduction in any medium, provided the original work is properly cited.

\begin{abstract}
The fatigue analysis on orthotropic steel bridge decks is a hot topic in bridge engineering field. This study provides one method for fatigue analysis under the combined actions of vehicle loads and pavement temperature. To be specific, taking the steel bridge deck of one cable-stayed bridge as a research object, this study proposes a method of calculating life-cycle fatigue damage of orthotropic steel deck under the combined actions of vehicle loads and pavement temperature. First, a finite element model of steel bridge deck with asphalt pavement is built to analyze the influence of pavement temperature on the fatigue stress of steel bridge deck. Second, a simulation method of fatigue stress caused by random vehicle loads is proposed. Finally, a method of calculating the life-cycle fatigue damage of welded joints under the combined actions of vehicle loads and temperature is proposed. The results show that temperature has a significant effect on fatigue damage, and the cumulative fatigue damage in the rib-to-rib welded joint is significantly greater than that in the deck-to-rib welded joint. The results can provide meaningful references for bridge engineers to carry out fatigue analysis on orthotropic steel bridge decks.
\end{abstract}

\section{Introduction}

The orthotropic steel deck has been widely used in bridge construction for the reason of effective load-carrying capacity, light weight, speedy construction, etc [1]. However, the service life of orthotropic steel deck has been limited due to fatigue cracks at welded joints [2]. Once fatigue cracking occurs, it will greatly endanger bridge performance. The first observed case of fatigue cracking was the Severn Bridge in 1971; subsequently, fatigue cracks were also detected in the orthotropic steel decks in Japan, the Netherlands, France, Belgium, etc. In China, serious fatigue cracks also exist in orthotropic steel decks, such as the Guangzhou Humen Bridge, Jiangyin Yangtze River Bridge, and Xiamen Bridge.

Traffic load and welded residual stress are two key causes of fatigue cracks of orthotropic steel decks. Many methods have been proposed for evaluation of fatigue resistance, such as nominal stress method, hot spot stress method, and notch stress method [3]. For example, Deng et al. studied the fatigue resistance of an orthotropic steel deck using nominal stress method and found that the average strain in the steel deck had little effect on fatigue stress spectra [4]. However, the welded residual stresses are not taken into consideration in these methods. In order to consider the welded residual, a modified Manson-Coffin equation was proposed to predict the fatigue life in low-cycle fatigue problems [5]. An energybased critical plane approach was developed to estimate fatigue life using the stochastic high-cycle nature of fatigue cracks [6]. In recent years, some research results showed that the fatigue life of steel deck was significantly correlated with seasonal temperatures [7]. An analysis of monitoring data from the Runyang Bridge revealed that temperature has a 
linear effect on fatigue damage [8]. In addition, an investigation showed that the fatigue life is considerably shortened by the effect of asphalt pavement temperature [9]. Therefore, it is necessary to propose a calculation method for fatigue evaluation considering the combined actions of traffic load and seasonal temperature.

Taking the orthotropic steel bridge deck of one cablestayed bridge as a research object, a method is proposed to calculate the life-cycle fatigue damage in the welded joints under the combined actions of vehicle loads and temperature. First, a finite element model of steel bridge deck with asphalt pavement is established to simulate the effect of asphalt pavement temperature on the fatigue stress of steel bridge deck. Then, the method of calculating fatigue stresses caused by random vehicle loads is studied. Finally, the method of calculating life-cycle fatigue damage under the combined actions of vehicle loads and pavement temperature is proposed.

\section{Influence of Pavement Temperature}

2.1. Description of Finite Element Model. The fatigue damage is sensitive to the asphalt pavement temperature. Therefore, to simulate the effect of asphalt pavement temperature on the fatigue damage, it is necessary to establish a finite element model of steel bridge deck with asphalt pavement. The model is assumed as follows: (1) the asphalt pavement is a continuous isotropic body; (2) because the bonding layer between pavement and steel bridge deck is thin, it is ignored. The model contains top plate (TP), bottom plate (BP), transverse diaphragm (TD), longitudinal diaphragm (LD), longitudinal rib (LR), and wind fairing (WF), as shown in Figure 1(a). Because the effect of fatigue stress in orthotropic steel bridge deck is treated as a local mechanical behavior, only a part of steel bridge deck is built for fatigue analysis, as shown in Figure 1(b) [7]. The model has a length of $18.5 \mathrm{~m}$ and a width of $0.39 \mathrm{~m}$. Its four-side boundary is constrained by hinge support. The LD is replaced by spring support, and the spring stiffness is $1.388 \times 10^{7} \mathrm{~N} / \mathrm{m}$. This model has been validated using the monitoring data of temperature and fatigue stress [7].

In this model, the shell element is selected for steel plate simulation, and the solid element is selected for pavement simulation. The mesh size is between $1.5 \mathrm{~mm}$ and $50 \mathrm{~mm}$. The steel plate and pavement are connected together by virtue of node coupling. The density and elastic modulus of steel plate are $7850 \mathrm{~kg} / \mathrm{m}^{3}$ and $206 \mathrm{GPa}$, respectively. The asphalt pavement is a double-layer pavement structure. The upper layer is epoxy asphalt concrete, and the lower layer is cast asphalt mixture. The density of double-layer asphalt pavement is $2450 \mathrm{~kg} / \mathrm{m}^{3}$. The pavement modulus is sensitive to pavement temperature, so a coefficient $K$ is used to describe the effect of pavement temperature $T$ on elastic modulus $E$ :

$$
K=\frac{E_{S}}{E}=10^{0.01693\left(T-T_{S}\right)},
$$

where $E_{S}$ denotes the standard elastic modulus of asphalt pavement at standard temperature $T_{S}$ and $E$ denotes the elastic modulus of asphalt pavement at temperature T. E can be further expressed as follows:

$$
E=K^{-1} \cdot E_{S}
$$

Equation (2) is used to calculate the elastic modulus of asphalt pavements at different temperatures [10]. According to the "Design of Highway Asphalt Pavement" [11], $T_{S}$ and $E_{S}$ are assigned with the values of $20^{\circ} \mathrm{C}$ and $1200 \mathrm{MPa}$, respectively. Then, $E$ is calculated as follows:

$$
E=1.2 \times 10^{0.01693(20-T)+3} .
$$

2.2. Analysis Result. In this section, the influence of pavement temperature on the fatigue stresses is studied. In the model, $A$ and $B$ are two measuring points, as shown in Figure 2, which correspond to the deck-to-rib welded joint and the rib-to-rib welded joint, respectively. The stresses caused by vehicle loads are a local mechanical behavior, which means that only the wheel loads near the measuring points have a significant effect on the stresses at the measuring points. Hence, only the wheel loads from the left or right side of vehicles are selected for stress calculation, as shown in Figure 2. The left or right side of the first axle has one wheel, and the left or right side of the second, third, or fourth axle has two wheels. The wheels are loaded in the middle of top plate, as shown in Figure 2(b). The vehicle loads are treated as vertical moving forces successively acting on the nodes in the moving direction, and the moving speed is set to $60 \mathrm{~km} / \mathrm{h}$. The pavement temperature ranges from $-10^{\circ} \mathrm{C}$ to $60^{\circ} \mathrm{C}$. Through finite element simulation, the fatigue stresses of the two welded joints at different temperatures are obtained, with the curves at $-10^{\circ} \mathrm{C}, 10^{\circ} \mathrm{C}, 30^{\circ} \mathrm{C}$, and $50^{\circ} \mathrm{C}$ shown in Figures 3 and 4 , respectively. It can be seen that the peak values of fatigue stresses increase as the pavement temperature increases, indicating that temperature indeed has an effect on fatigue stresses. The reason is that the change of pavement temperature alters the elastic modulus of pavement, which further affects the transfer pressures in the pavement caused by vehicle loads.

The correlation between fatigue stress $S(T, t)$ and temperature $T$ at time $t$ is further studied. The values of stress and temperature at $t=0.768 \mathrm{~s}$ are selected from the simulated data, and their correlation is plotted in Figure 5. This correlation is expressed using the function $S(T, t=0.768 \mathrm{~s})=a T^{2}+b T+C$, as shown in Figure 5 . This function can be used to calculate the fatigue stresses at any temperature $T$ at $t=0.768 \mathrm{~s}$. Moreover, it can be analogized that the fatigue stresses at any temperature $T$ at any other time $t$ can also be calculated.

\section{Influence of Vehicle Loads}

3.1. Simulation of Random Vehicle Loads. The "Guidelines for the Design and Maintain of Orthotropic Steel Deck System" specifies four parameters for the vehicle model, which are vehicle weight, axle number, wheelbase, and axle load. However, it does not provide the parameters of vehicle 


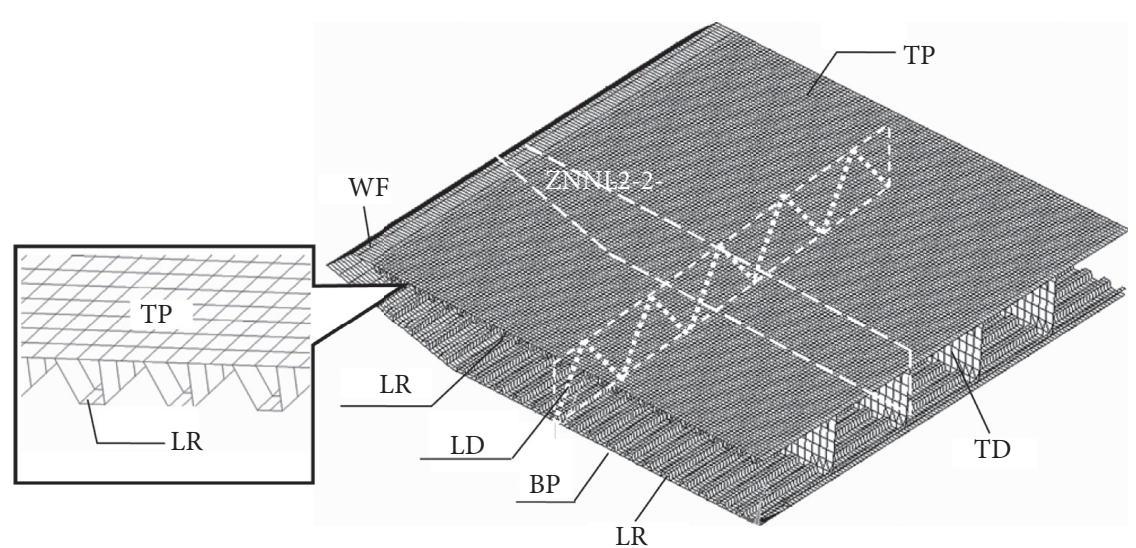

(a)

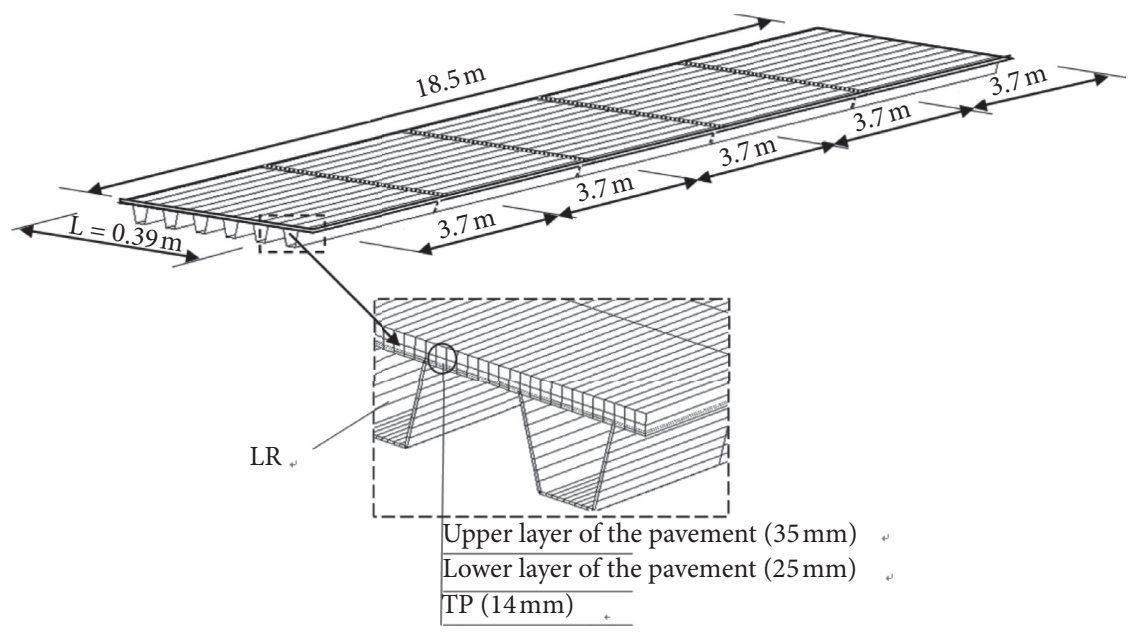

(b)

Figure 1: The finite element model: (a) the original model and (b) the simplified model.

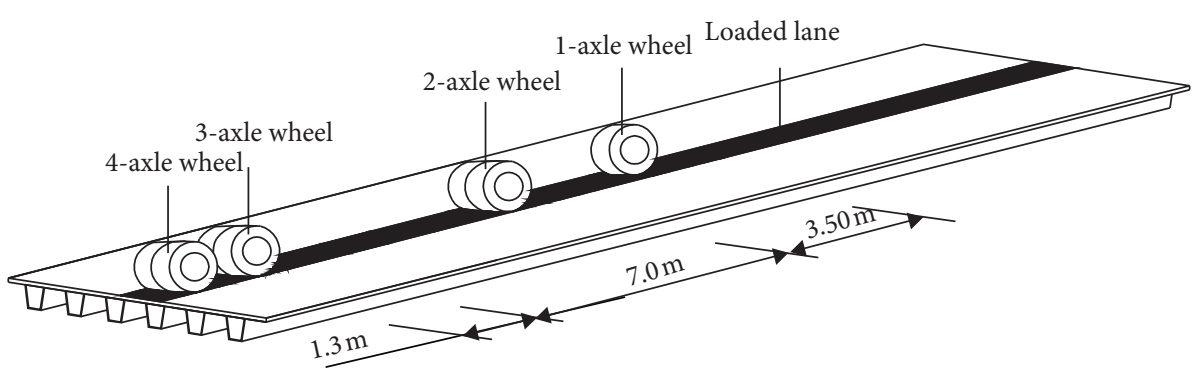

(a)

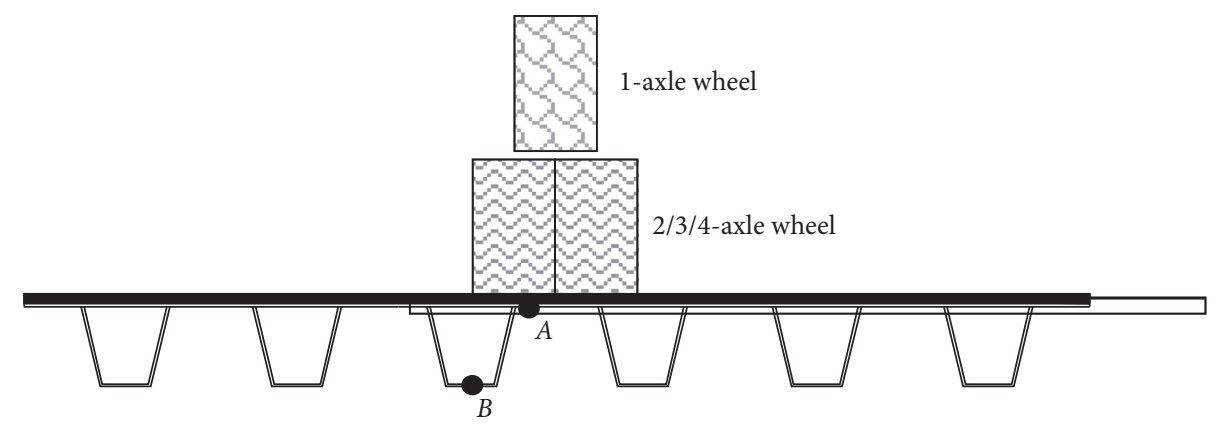

(b)

FIGURE 2: Loading locations and measuring points: (a) wheel load in the longitudinal direction and (b) wheel load in the transversal direction. 


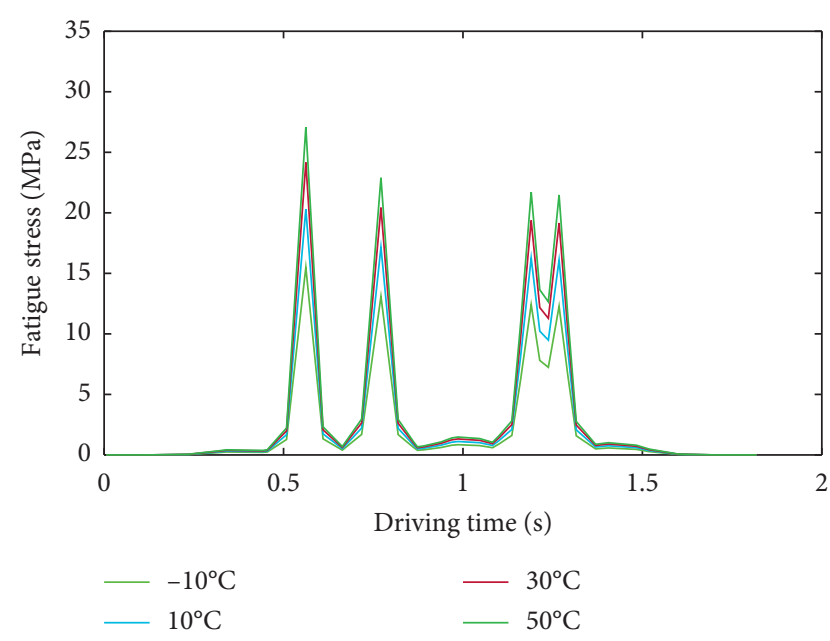

Figure 3: The fatigue stresses at different temperatures at monitoring point $A$.

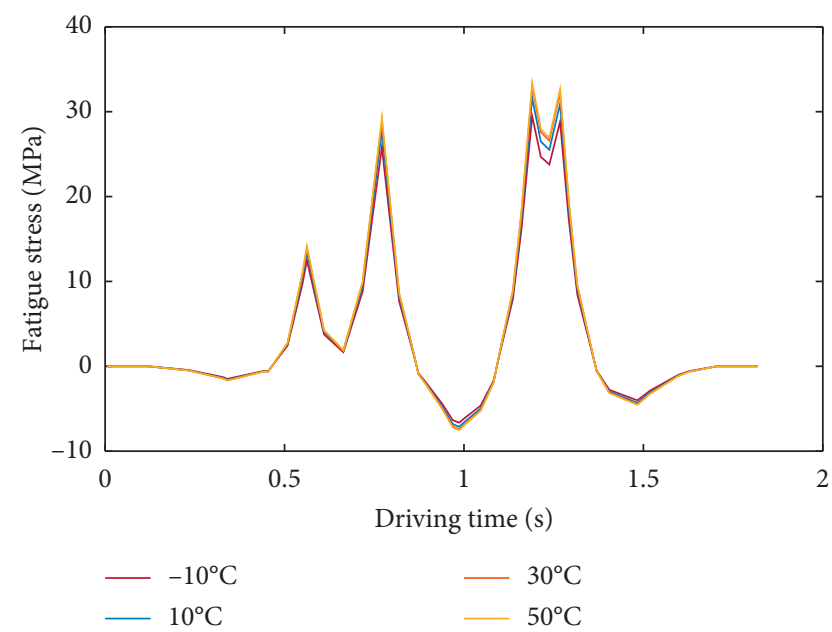

Figure 4: The fatigue stresses at different temperatures at monitoring point $B$.

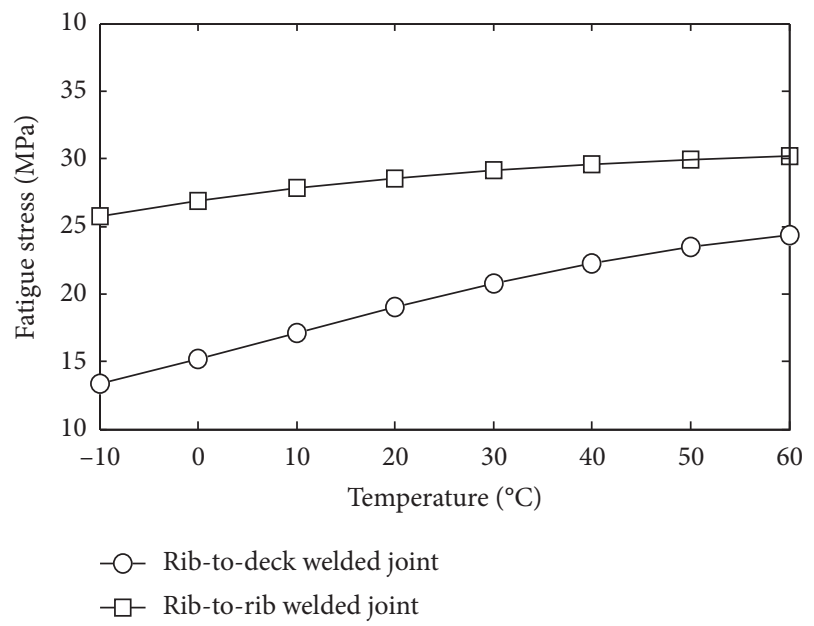

Figure 5: The correlation between fatigue stress and temperature. spacing and driving speed [12]. Hence, it is necessary to simulate these two parameters.

3.1.1. Statistical Model of Vehicle Spacing and Driving Speed. The vehicle spacing and driving speed are denoted by $s$ and $v$, respectively. The distribution function of $s$ follows the logarithmic normal distribution with $\mu=2.2451$ and $\sigma=1.3497$ [13], which is expressed as follows:

$$
f(s)=\frac{1}{s \sigma \sqrt{2 \pi}} e^{(\ln s-\mu)^{2} / 2 \sigma^{2}},
$$

where $f(s)$ denotes the probability density function of $s$.

With regard to $v$, the distribution function is indirectly determined. The time of the rear axle of the previous car passing through an observation point is denoted by $t_{A}$, and the time of the front axle of the next car passing through the same observation point is denoted by $t_{B}$. Then, the time span between $t_{A}$ and $t_{B}$ is denoted by $\Delta t$, which follows the exponential distribution as follows [13]:

$$
f(\Delta t)=\frac{1}{\mu} e^{-(\Delta t / \mu)},
$$

where $f(\Delta t)$ is the probability density function of $\Delta t$ and $\mu=0.0436$. Furthermore, the distribution function of $v$ is expressed as follows:

$$
f(v)=\frac{f(s)}{f(\Delta t)} .
$$

\subsubsection{Monte Carlo Sampling}

(1) Monte Carlo Method. The random values of $s$ and $v$ can be determined using Monte Carlo sampling. The Monte Carlo method is a method that uses statistical sampling theory to approximately solve mathematical problems $[14,15]$. It can generate a series of random values in a given interval for random variables $[14,15]$. For example, as for a random variable $X$ subjected to the distribution function $F(X)$, the random values in the given interval $(-\infty,+\infty)$ can be generated as follows:

$$
X=F^{-1}[\operatorname{rand}(0,1)] .
$$

Moreover, the random numbers in the given interval ( $a$, b) can be generated as follows:

$$
X=F^{-1}\{F(a)+[F(b)-F(a)] \cdot \operatorname{rand}(0,1)\},
$$

where $F$ and $F^{-1}$ are the distribution function and inverse function, respectively, and rand $(0,1)$ denotes uniform random sampling in the internal $(0,1)$. If the probability density function $f(X)$ is given, $F(\mathrm{a})$ and $F(\mathrm{~b})$ can be determined.

(2) Sampling Interval. The traffic management department in China has specified the limits of safe distance and speed for moving vehicles. Hence, it is necessary to take the upper and lower limits of $s$ and $t$ into consideration. As for the random variable $s$, its lower limit is determined by the following formula: 


$$
s_{\min }=\left(T_{1}+T_{2}\right) V_{\mathrm{BO}}+L_{\text {safe }},
$$

where $T_{1}$ is the driver's reaction time (unit, s); $T_{2}$ is the brake coordination time (unit, $s$ ); $V_{\mathrm{BO}}$ is the initial speed of the following vehicle at the time of braking (unit, $\mathrm{m} / \mathrm{s}$ ); and $L_{\text {safe }}$ is the smallest distance to ensure safety when the running vehicle is braked to stop (unit, $\mathrm{m}$ ). Some studies have revealed that the values of $T_{1}, T_{2}, V_{\mathrm{BO}}$, and $L_{\mathrm{safe}}$ are $0.56 \mathrm{~s}$, $0.175 \mathrm{~s}, 13.9 \mathrm{~m} / \mathrm{s}$, and $3 \mathrm{~m}$, respectively [16]. $S_{\min }$ is $13.2 \mathrm{~m}$ after calculation using these values. According to the monitoring data, the maximum distance $S_{\max }$ between moving vehicles is set to $1000 \mathrm{~m}$. Hence, the interval of $s$ is (13.2 1000).

The upper and lower limits of $\Delta t$ relate to the vehicle spacing $s$ and the driving speed $v$, which is written as $\Delta t=s / v$. The maximum and minimum values of $\Delta t$ are determined using the upper and lower limits of $s$ and $v$, which are $\Delta t_{\min }=$ $s_{\min } / v_{\max }=0.432 \mathrm{~s}$ and $\Delta t_{\max }=s_{\max } / v_{\min }=72 \mathrm{~s}$. Hence, the interval of $\Delta t$ is $(0.43272)$.

(3) Sampling Result. Monte Carlo sampling is performed using equation (8), with the results shown in Figure 6. The results have good agreement with the probabilistic density functions. The values of $v$ are determined using the equation $v=s / t$. After the values of parameters of the vehicle load model are determined, many moving vehicles are randomly simulated, which are arranged in a unified timeline, as shown in Figure 7. The first axle of the $i$ th vehicle passes through the observation point at speed $v_{i}$. The last axle of the $i$ th vehicle passes through the observation point after the time interval $11.8 / v_{i}$ (11.8 is the vehicle wheelbase). The first axle of the $(i+1)$ th vehicle passes through the observation point at speed $v_{i+1}$ after the time interval $t_{i}$.

\subsection{Calculation of Fatigue Stress under Random Vehicle Loads.} Fatigue stress has a linear correlation with wheel weight, and the fatigue stresses caused by different wheel weights can be linearly superposed [17]. Therefore, the total fatigue stress caused by all the random vehicle loads can be obtained through the linear superposition of fatigue stress caused by each vehicle load.

The fatigue stress caused by one vehicle passing through the finite element model at different speeds is calculated first. In Section 2, the fatigue stresses were calculated when a vehicle passed through the finite element model at a driving speed of $60 \mathrm{~km} / \mathrm{h}$ (Figures 3 and 4). Therefore, the fatigue stresses caused by a vehicle at a driving speed $v_{i}$ is obtained by multiplying the time with a proportional coefficient $60 / v_{i}$. Figure 8 shows the fatigue stresses of the rib-to-deck welded joint when a vehicle passes through the finite element model at $50 \mathrm{~km} / \mathrm{h}, 70 \mathrm{~km} / \mathrm{h}, 90 \mathrm{~km} / \mathrm{h}$, and $110 \mathrm{~km} / \mathrm{h}$, respectively.

After the fatigue stresses caused by each vehicle at running speed $v_{i}$ are obtained, it is necessary to integrate them to a unified timeline according to the occurrence time of each vehicle. If the fatigue stress caused by the $(i-1)$ th vehicle occurs at time $t_{r}$ in the timeline, it can be inferred that the occurrence time of fatigue stress caused by the $i$ th vehicle in the timeline is $t_{r}+\Delta t_{i}$, where $\Delta t_{i}$ is the time span between $t_{A}$ and $t_{B}$. The fatigue stresses of all the vehicles are arranged in the unified timeline in the order of occurrence time. Then, the fatigue stresses at the same time are linearly superposed together to obtain the total fatigue stress at the same time. Figure 9 shows the fatigue stresses of two welded joints when the pavement temperature is $10^{\circ} \mathrm{C}$.

\section{The Life-Cycle Fatigue Damage Analysis}

4.1. Life-Cycle Simulation of Pavement Temperature. Some results have shown that the temperature gradients in the pavement are small $[7,18]$, so this study only studies the effect of uniform temperature on the fatigue damage. The monitoring temperature data are short-term data only measured in several years, which should be extended to become long-term temperature data $T_{\text {life }}$ in the whole service life for calculation of life-cycle fatigue damage. The monitoring result of uniform temperature in steel decks has shown that the uniform temperature follows normal distribution, so the long-term temperature data $T_{\text {life }}$ is obtained by virtue of normal distribution, which has been concretely introduced in [18].

4.2. The Life-Cycle Fatigue Damage Caused by Vehicle and Temperature. Through the simulation of random vehicle load and long-term pavement temperature, the fatigue damage in any time span $\Delta P$ is calculated. First, the vehicle loads in the time span $\Delta P$ are randomly simulated. Then, each curve of fatigue stress caused by single vehicle and temperature of $10^{\circ} \mathrm{C}$ is located in the unified timeline. Through simulation of pavement temperature, the temperature variation $T$ in $\Delta P$ is simulated at any time $t$. According to the correlation between $S(T, t)$ and $T$, the fatigue stresses caused by single vehicle at any temperature $T$ and time $t$ are obtained in the unified timeline. The fatigue stresses at the same time are linearly superposed to obtain the total fatigue stress caused by all the vehicles at any temperature $T$ and any time $t$. The simulated fatigue stresses in the two welded joints under the combined actions of vehicle loads and temperatures in one year are shown in Figure 10.

The simulated fatigue stresses are analyzed using the "rain-flow counting" method. The equivalent stress amplitude $S_{\text {eq }}$ and the number of stress cycles $N_{\mathrm{d}}$ in 365 days are calculated. 36 representative values are uniformly selected from 365 days of $S_{\text {eq }}$, as shown in Figure 11. It can be seen that the trend of $S_{\text {eq }}$ shows notable seasonal variation characteristics, i.e., the values in summer are bigger than that in winter. In addition, 36 representative values are uniformly selected from 365 days of $N_{\mathrm{d}}$, as shown in Figure 12. It can be seen that the trend of $N_{\mathrm{d}}$ does not show any seasonal variation characteristics. The result indicates that $S_{\text {eq }}$ is sensitive to temperature, while $N_{\mathrm{d}}$ is not sensitive to temperature. Hence, the influence of temperature on $S_{\text {eq }}$ should be taken into consideration for fatigue analysis.

The fatigue damage $D$ in each day is further calculated using the data of $S_{\text {eq }}$ and $N_{\mathrm{d}}$, which are plotted in Figure 13. It can be seen that the fatigue damage also shows notable 


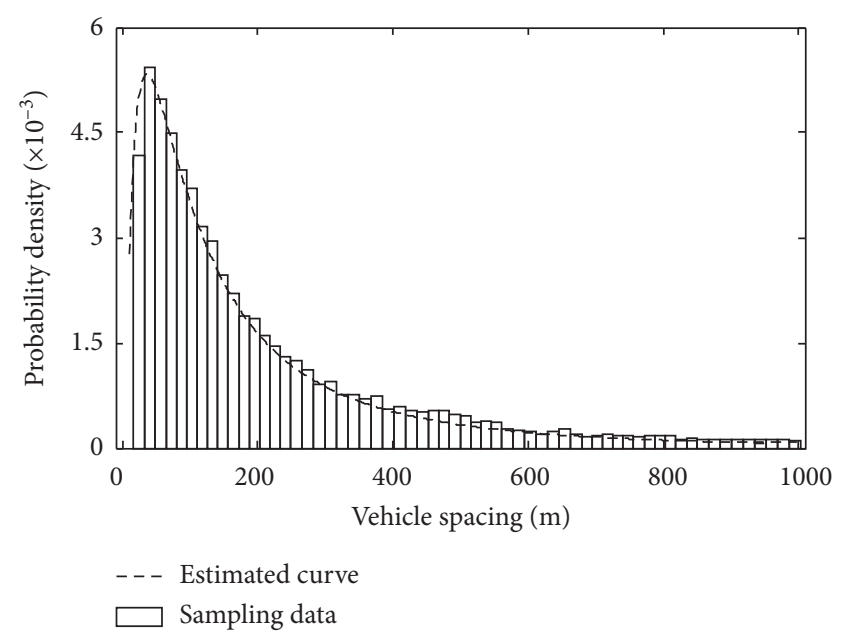

(a)

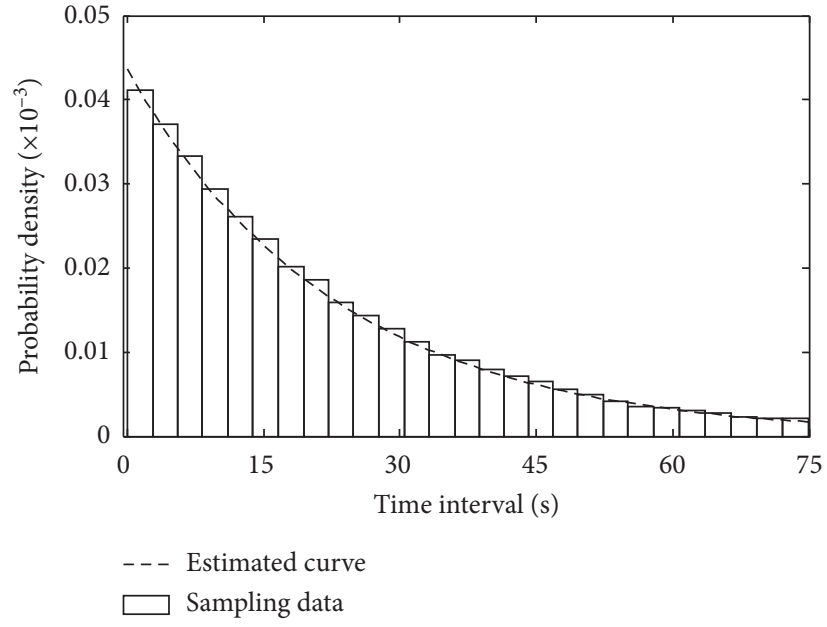

(b)

Figure 6: The sampling results of $s$ and $t$ : (a) random variable $s$ and (b) random variable $t$.

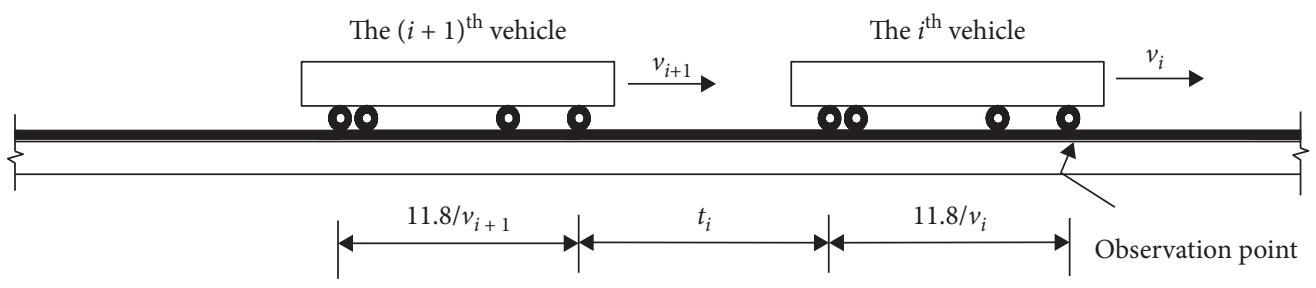

Figure 7: Simulation diagram of random vehicle loads.

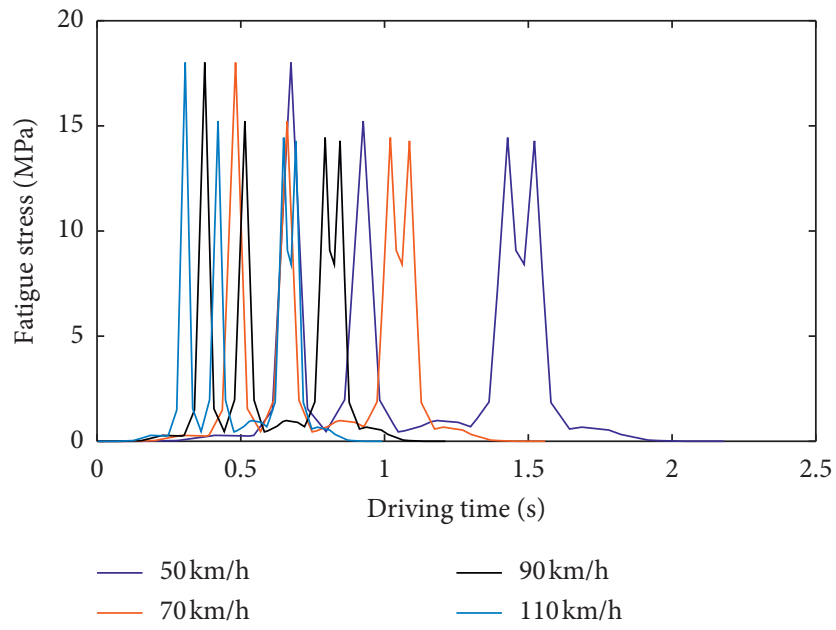

FIgURE 8: The fatigue stresses at different vehicle speeds.

seasonal variation characteristics, indicating that fatigue damage is evidently affected by temperature for the reason of high sensitivity of $S_{\text {eq }}$ to temperature.

The average temperature in each day is denoted by $\bar{T}$, and the correlation between $D$ and $\bar{T}$ is plotted in Figure 14, which shows a notable relationship. Therefore, one suggestion for bridge researchers is to pay enough attention to the temperature effect on fatigue damage. Assume that the relationship is expressed by the function $D=a \bar{T}^{2}+b \bar{T}+c$. The least-square method is used to determine the parameter values $a, b$, and $c$, with the results shown in Table 1. This function can provide reference for bridge engineers to consider the temperature-affected fatigue damage. 


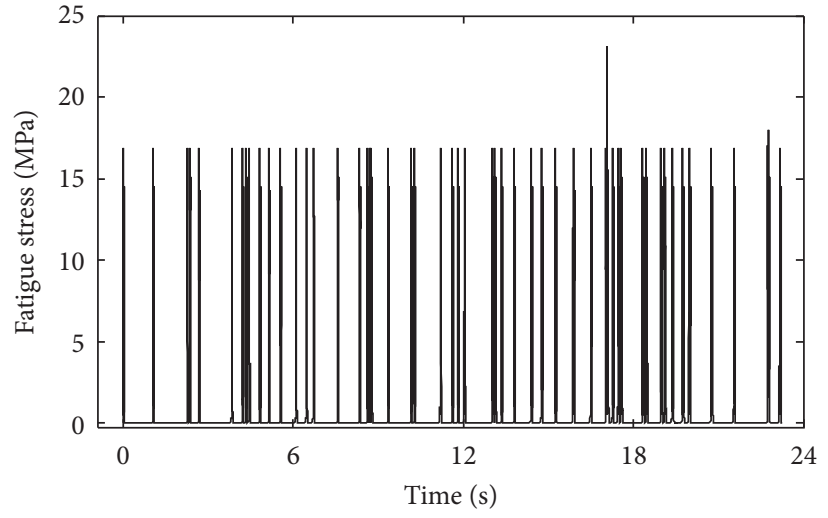

(a)

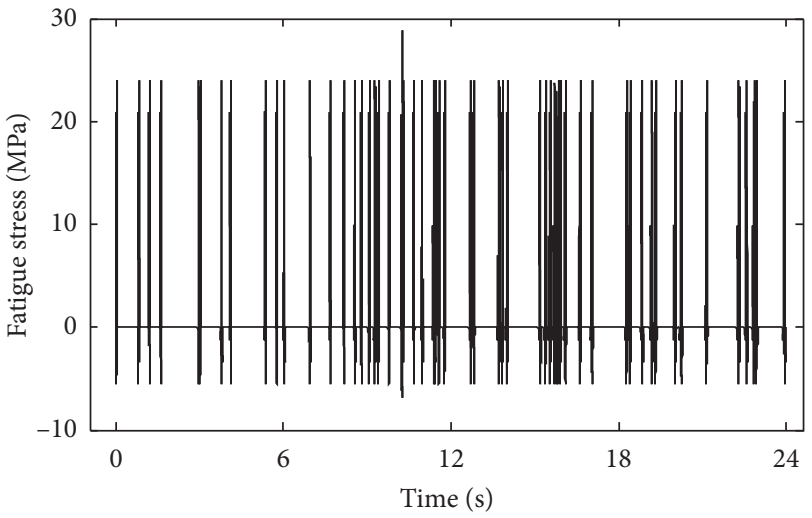

(b)

FIGURE 9: Fatigue stress: (a) the rib-to-deck welded joint and (b) the rib-to-rib welded joint.

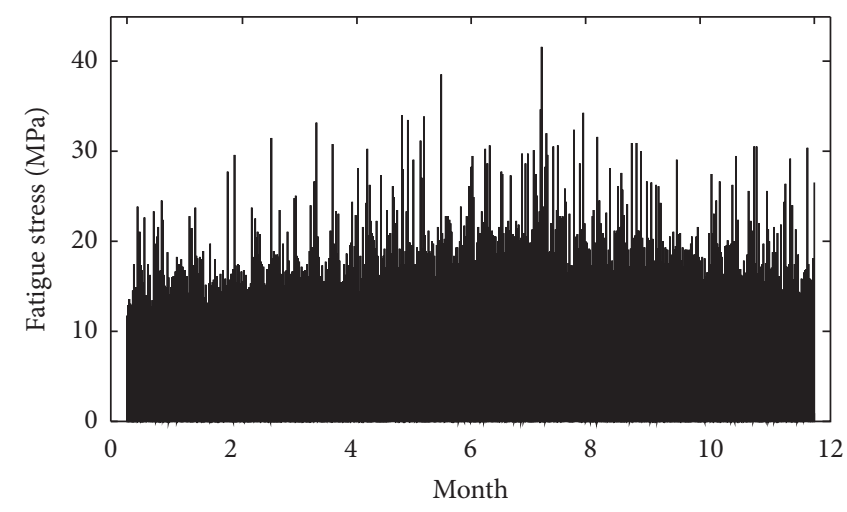

(a)

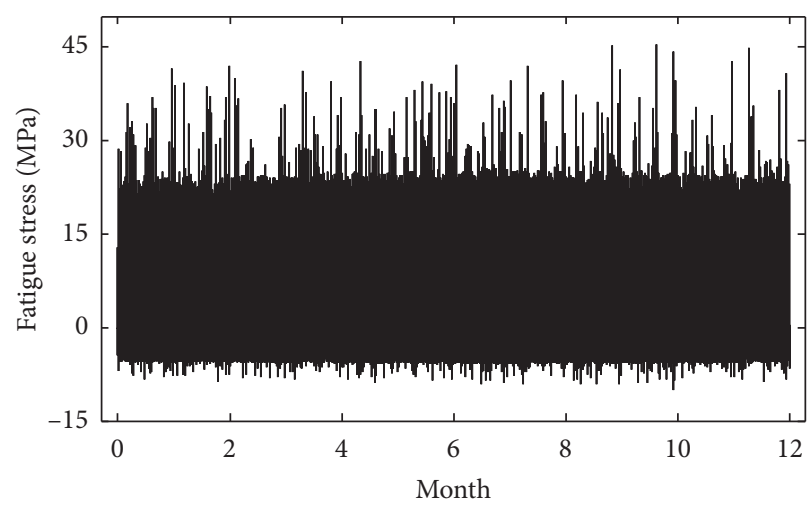

(b)

FIgURE 10: The fatigue stresses: (a) the rib-to-deck joint and (b) the rib-to-rib joint.

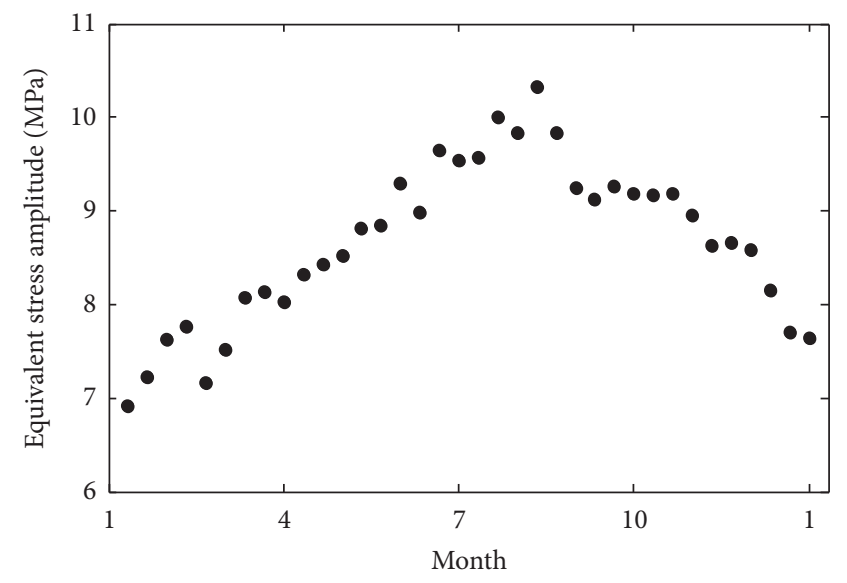

(a)

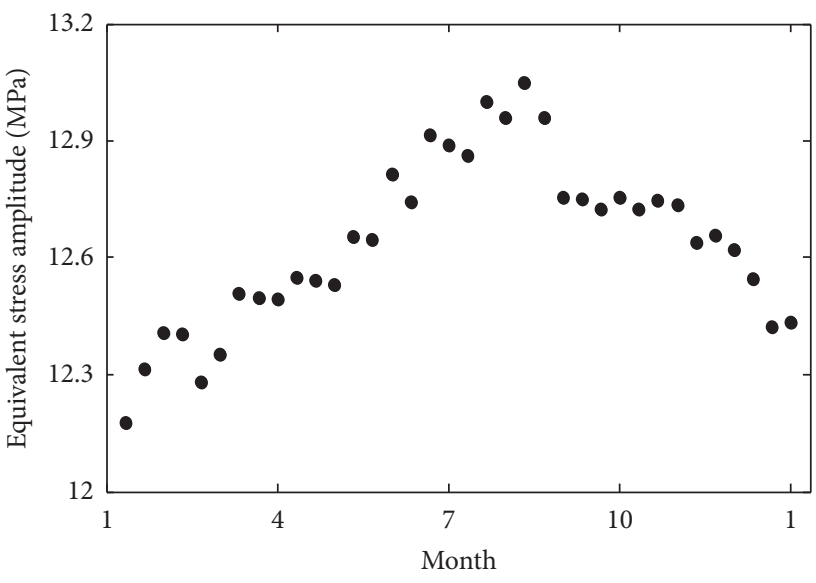

(b)

Figure 11: The scattered diagrams of $S_{\text {eq }}$ : (a) the rib-to-deck joint and (b) the rib-to-rib joint.

Furthermore, the fatigue damage in 100 years is calculated, as shown Figure 15. The cumulative fatigue damage in 100 years is 0.115 for the rib-to-deck welded joint and is
0.692 for the rib-to-rib welded joint. It can be seen that the cumulative fatigue damage of the rib-to-rib welded joint is noticeably greater than that of the rib-to-deck welded joint. 


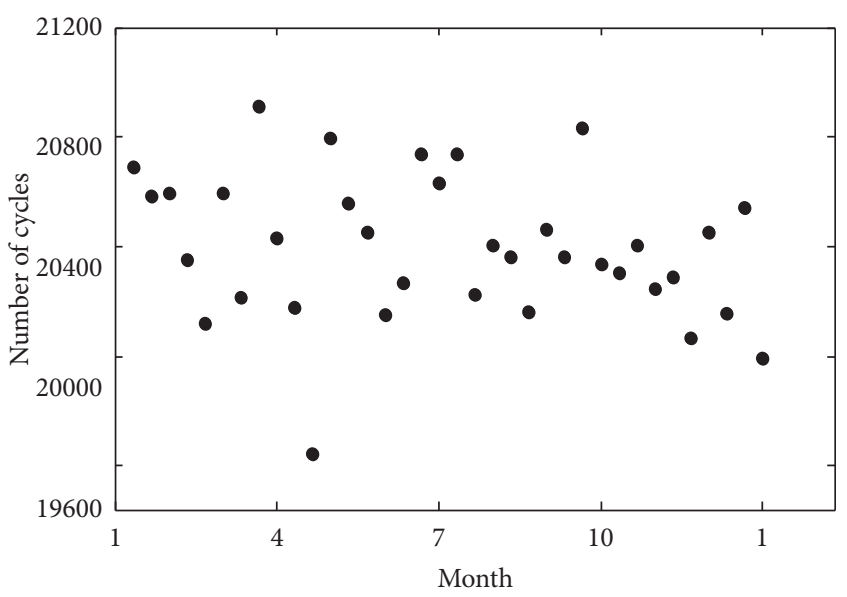

(a)

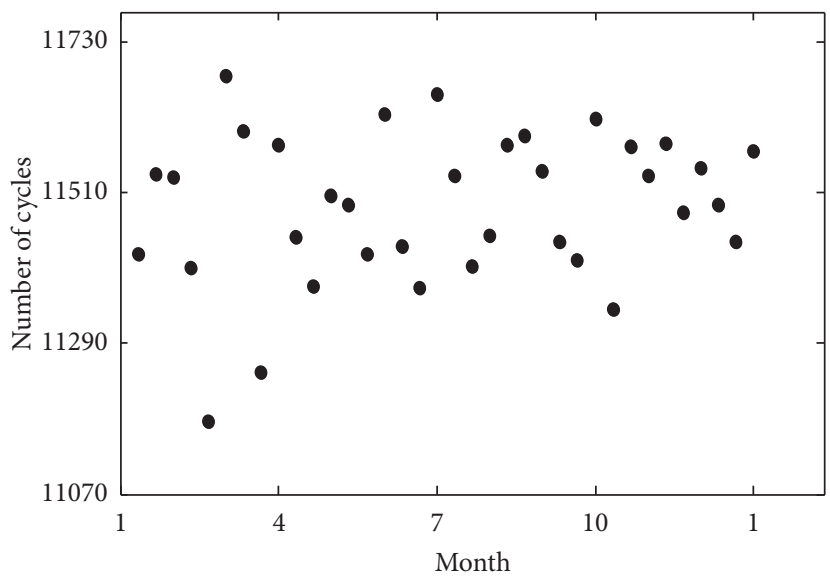

(b)

FIgURE 12: The scattered diagrams of $N_{\mathrm{d}}$ : (a) the rib-to-deck joint and (b) the rib-to-rib joint.

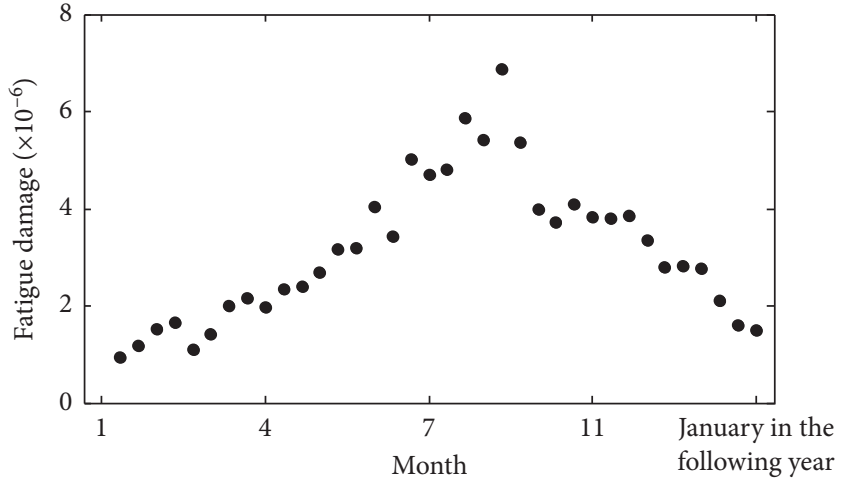

(a)

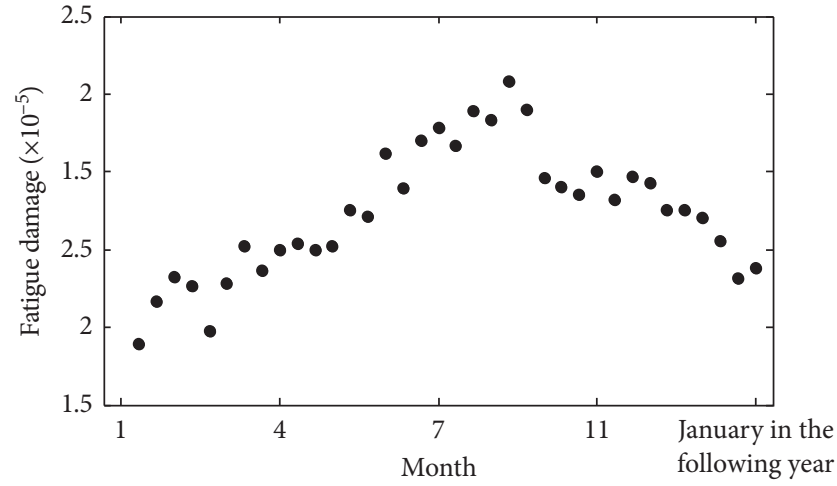

(b)

FIgURE 13: The scatter diagrams of fatigue damage: (a) the rib-to-deck joint and (b) the rib-to-rib joint.

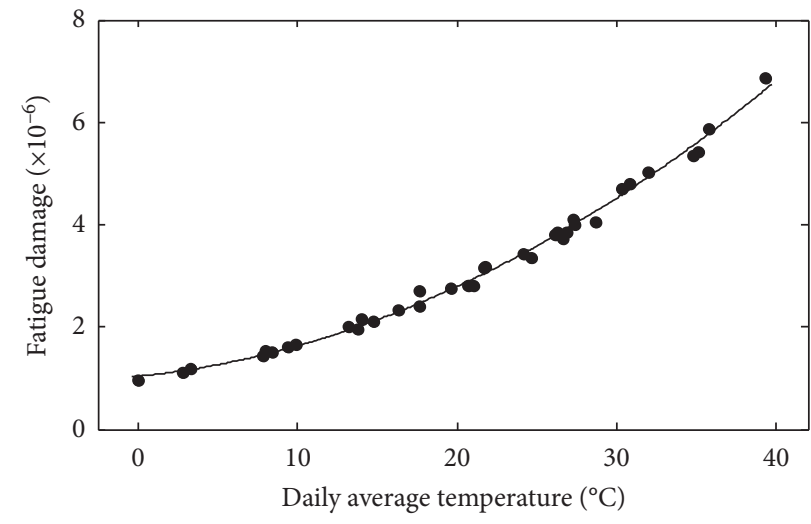

- Daily fatigue damage

- Fitted curve

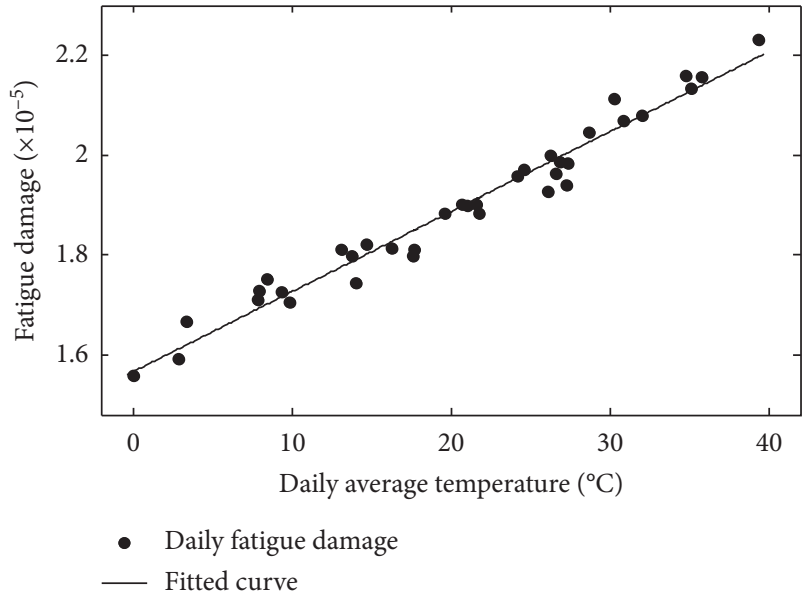

(b)

Figure 14: The correlation between $D$ and $\bar{T}$ : (a) the rib-to-deck joint and (b) the rib-to-rib joint. 
TABle 1: Parameters of the correlation.

\begin{tabular}{lcc}
\hline Model parameter $\left(\times 10^{-6}\right)$ & Welded joints & Rib-to-rib welded joint \\
\hline$A$ & Rib-to-deck welded joint & 0.000 \\
$B$ & 0.003 & 0.160 \\
$C$ & 0.031 & 15.660 \\
Correlation coefficient $r$ & 1.038 & 0.966 \\
\hline
\end{tabular}

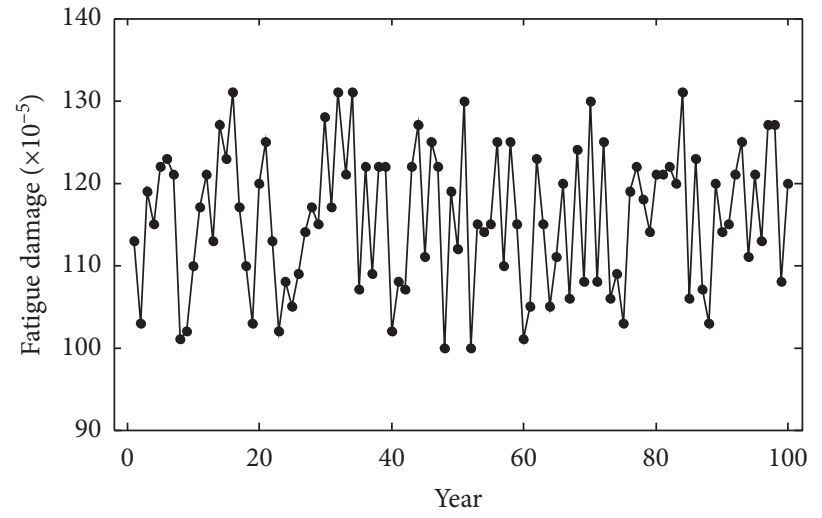

(a)

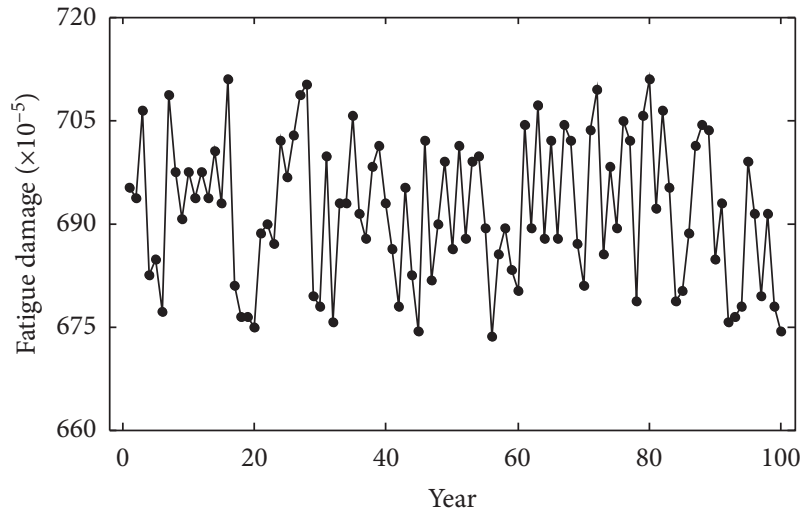

(b)

Figure 15: 100-year fatigue damages: (a) the rib-to-deck joint and (b) the rib-to-rib joint.

Therefore, a suggestion for bridge engineers is to concern more on the rib-to-rib welded joints.

\section{Conclusions}

In this study, using the orthotropic steel bridge deck of a cable-stayed bridge as a case study, a method is proposed for calculating the life-cycle fatigue damage in the welded joints of steel bridge deck under the combined actions of vehicle loads and pavement temperature. The main conclusions are drawn as follows:

(1) The peak values of fatigue stresses increase as pavement temperature increases, indicating that temperature has an effect on fatigue stresses. The reason is that temperature change in pavement alters the elastic modulus of pavement, which further affects the transfer pressures in the pavement caused by vehicle loads. One suggestion for bridge engineers is to pay enough attention to the temperature effect on fatigue damage.

(2) This research proposed one method of calculating fatigue stress with consideration of vehicle load and pavement temperature. The total fatigue stress at a time point caused by all the vehicle loads and pavement temperature is obtained by the linear superposition of the fatigue stresses caused by each vehicle load and temperature at the same time point.

(3) The equivalent stress amplitude shows notable seasonal variation characteristics, and the number of stress cycles does not show any seasonal variation characteristics. This indicates that equivalent stress amplitude is sensitive to seasonal temperature, which should be paid much attention during fatigue analysis. The fatigue damage also shows notable seasonal variation characteristics, indicating that fatigue damage is evidently affected by temperature.

(4) The 100-year cumulative fatigue damage is 0.115 for the rib-to-deck welded joint and is 0.692 for the rib-to-rib welded joint. Both of the values are less than 1, indicating no fatigue damage occurs for the two types of welded joints in the 100-year lifetime service. In addition, the cumulative fatigue damage of the rib-to-rib welded joint is noticeably greater than that of the rib-to-deck welded joint, so one suggestion for bridge engineers is to concern more on the rib-to-rib welded joints.

\section{Data Availability}

The data used to support the findings can be obtained by contacting via civilchina@hotmail.com.

\section{Conflicts of Interest}

The authors declare that there are no conflicts of interest regarding the publication of this paper.

\section{Acknowledgments}

The authors gratefully acknowledge the Fundamental Research Funds for the Central Universities (2017XKQY050). 


\section{References}

[1] Z. Fu, Y. Wang, B. Ji, and F. Jiang, "Effects of multiaxial fatigue on typical details of orthotropic steel bridge deck," ThinWalled Structures, vol. 135, pp. 137-146, 2019.

[2] P. Luo, Q. Zhang, Y. Bao, and A. Zhou, "Fatigue evaluation of rib-to-deck welded joint using averaged strain energy density method," Engineering Structures, vol. 177, pp. 682-694, 2018.

[3] C. Cui, Y. Z. Bu, Y. Bao, Q. H. Zhang, and Z. T. Ye, "Strain energy-based fatigue life evaluation of deck-to-rib welded joints in OSD considering combined effects of stochastic traffic load and welded residual stress," Journal of Bridge Engineering, vol. 23, no. 2, Article ID 04017127, 2018.

[4] Y. Deng, Early Warning and Evaluation Method for LargeSpan Bridge Structures Based on Long-Term Monitoring Data and Its Application, Southeast University, Nanjing, China, 2009, in Chinese.

[5] G. A. Webster and A. N. Ezeilo, "Residual stress distributions and their influence on fatigue lifetimes," International Journal of Fatigue, vol. 23, no. S1, pp. 375-383, 2001.

[6] K. C. Liu and J. A. Wang, "An energy method for predicting fatigue life, crack orientation, and crack growth under multiaxial loading conditions," International Journal of Fatigue, vol. 23, no. S1, pp. 129-134, 2001.

[7] G. Wang, Y. Ding, Y. Song, and W. Zheng, "Influence of temperature action on the fatigue effect of steel deck with pavement," Engineering Mechanics, vol. 33, no. 5, pp. 115-123, 2016, in Chinese.

[8] T. Guo, A. Q. Li, and Z. X. Li, "Influence of temperature and increasing traffic flow on the fatigue damage of welded bridge decks," Advances in Fracture and Damage Mechanics VI, vol. 348-349, pp. 341-344, 2007.

[9] M. Li, K. Hashimoto, and K. Sugiura, "Influence of asphalt surfacing on fatigue evaluation of rib-to-deck joints in orthotropic steel bridge decks," Journal of Bridge Engineering, vol. 19, no. 10, Article ID 04014038, 2014.

[10] X. Cha, "Temperature adjustment for back calculation modulus of asphalt pavement," Highway, no. 4, pp. 51-53, 2002, in Chinese.

[11] JTG D 50-2017, Specifications for Design of Highway Asphalt Pavement, China Communications Press, Beijing, China, 2017, in Chinese.

[12] CCCC Highway Consultants Co.,Ltd., Guidelines for Design and Maintenance of Orthotropic Steel Deck, CCCC Highway Consultants Co.,Ltd., Beijing, China, 2010, in Chinese.

[13] Highway Bridge Vehicle Load Research Group, "Research on vehicle loads of highway bridges," Highway, no. 3, pp. 8-12, 1997, in Chinese.

[14] J. A. Acebron, "A Monte Carlo method for computing the action of a matrix exponential on a vector," Applied Mathematics and Computation, vol. 362, Article ID 124545, 2019.

[15] Z. P. Guo and Z. M. Deng, "Interval identification of structural parameters using interval deviation degree and Monte Carlo simulation," International Journal of Computational Methods, vol. 16, no. 7, Article ID 1850103, 2019.

[16] A. Zheng and B. Zhang, "Safety distance under different following states on expressway," Journal of Wuhan University of Science and Technology (Natural Science Edition), vol. 26, no. 1 , pp. 54-57, 2003, in Chinese.

[17] L. Frýba and L. Gajdoš, "Fatigue properties of orthotropic decks on railway bridges," Engineering Structures, vol. 21, no. 7, pp. 639-652, 1999.

[18] Y. Ding, G. Wang, G. Zhou, and A. Li, "Life-cycle simulation method of temperature field of steel box girder for Runyang cable-stayed bridge based on field monitoring data," China Civil Engineering Journal, vol. 46, no. 5, pp. 129-136, 2013, in Chinese. 